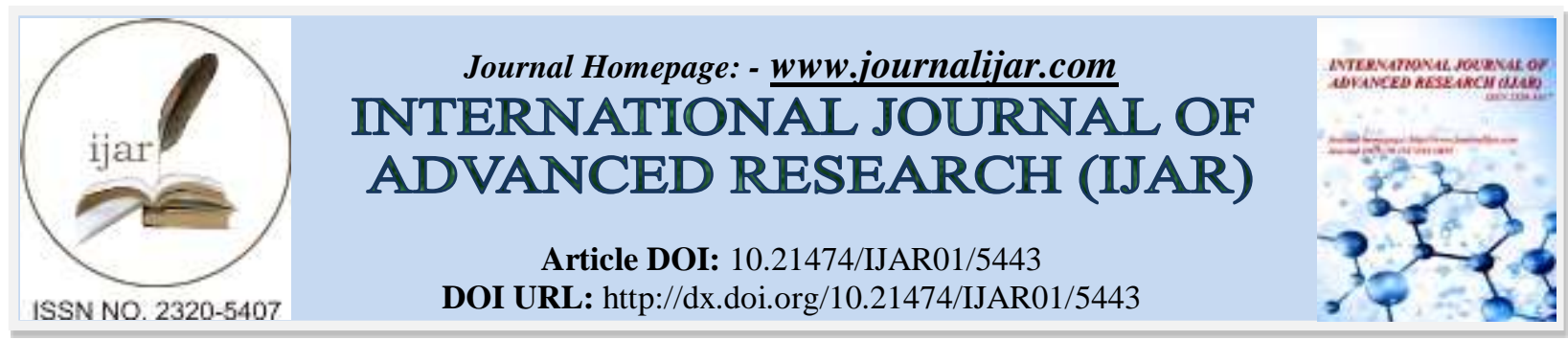

RESEARCH ARTICLE

\title{
HAIR DISTRIBUTION ON THE DORSUM OF THE HUMAN HAND PHALANGES IN COMPARISON WITH SEMINAL FLUID PARAMETERS.
}

\author{
Mohammad Oda Selman (FIBMS), Khalid Al Azaawi (MSc) and Hikmat Fakhri Wassef. (MSc). \\ High Institute for Infertility Diagnosis and Treatment / Al Nahrain University.
}

\section{Manuscript Info}

Manuscript History

Received: 16 July 2017

Published: September 2017

Key words:-

Mid-phalangeal Hair, Proximal
Final Accepted: 18 August 2017 phalangeal and Seminal fluid analysis.

\begin{abstract}
Background: Hair is a filamentous keratinized structure present over almost all of the body surface. It is a derivative of the epidermis which assists in thermoregulation and provides some protection against injury. Probability of incidence of hair distribution was also studied among the dorsum of phalanges of the $2^{\text {nd }}$ to $5^{\text {th }}$ fingers of both hands.

Objectives: The aim of the study to assess the different patterns and frequency of the distribution of the phalangeal hair of the hands of Iraqi males' population in correlation with seminal fluid parameters.

Methods: The subjects studied were (350) male. All subjects were born in Iraq and aged between 18 and 58 years. The observations were made using a hand lens in daylight. Presence or absence of hair over each phalanx of the right and left hand, age and seminal fluid analysis of each subject were recorded.

Results: The results was shown a significant difference between study group and control group in hair distribution on the dorsum of phalanges of the fingers of right and left hands. In left hand phalanges of proximal and middle $(\mathrm{P}<0.05)$ but on index there was non-significant $(\mathrm{P}>0.082)$. While significant difference $(\mathrm{P}<0.05)$ in proximal of right hand phalanges. Non-significant $(\mathrm{P}>0.05)$ in index and middle fingers of right hands

Discussion: Many studies show that the majority of individuals have hair on the proximal and middle phalanges of the right and left hand but no on the distal phalanges. The highest percentage of hair distribution was observed in the proximal phalanges. The significant variation in the pattern and number of hair on the phalanges may be due to hormonal effect during intrauterine life.
\end{abstract}

Copy Right, IJAR, 2017,. All rights reserved.

\section{Introduction:-}

Hair is a filamentous keratinized structure present over almost all of the body surface ${ }^{(1)}$. It is a derivative of the epidermis which assists in thermoregulation and provides some protection against injury ${ }^{(2,3)}$. Hairs begin development as solid epidermal proliferations from the germinative layer that penetrates the underlying dermis.

Hair distribution on the dorsum of phalanges of the hand was studied on Chinese subjects (males and females) randomly selected. Chinese females showed a significantly lower $(\mathrm{p}<0.05)$ incidence of proximal phalangeal hair on the hands than Chinese males ${ }^{(4)}$. 
Racial differences in the distribution of hair over the phalanges studied was reported ${ }^{(5,6)}$. The distribution of the phalangeal hair of the hands has been investigated in Turks. Hair was absent over the proximal phalanx in 1-7 \% of females and in $0-2 \%$ of males ${ }^{(7)}$.

In Malays subjects hair distribution on the phalanges of their hands. Hair on the proximal phalanx was absent in $2 \%$ of the males and in 3.3\% of the females. The middle phalangeal hair (MPH) was absent in $78 \%$ of the females and in $64.9 \%$ of the males ${ }^{(8)}$. Age was not a factor had effect on hair distribution ${ }^{(9)}$.

Probability of incidence of hair distribution was also studied among the fingers of both the hands. This correlation was significant on the proximal phalanges ${ }^{(10)}$. Middle phalangeal hair of the fingers varies in quantity and distribution among different human groups. Data on middle phalangeal hair among unrelated autochthonous individuals show remarkable sexual differences in the Murcia population ${ }^{(11)}$.

Data relating to middle phalangeal hair (MPH) among unrelated individuals of both sexes born and living in Sardinia are presented. The occurrence of MPH is generally manifested on the 3-4-5 digits of both hands in the two sexes ${ }^{(12)}$.

The aim of this study was to assess the different patterns and frequency of hair distribution on the phalanges of the population studied. The present work presents findings from Iraq.

\section{Material and Methods:-}

The study participants were randomly selected from the High Institute of Infertility Diagnosis and Assisted Reproductive Technologies, AL-Nahrain University (AL-Kadhumiya) Baghdad-Iraq, all of which were of Iraqi descent. A total of 350 healthy males aged 18- 58 years were recruited from October, 2015 to April, 2016. The presence or absence of hair on the proximal and middle phalanges of both hands was observed using a hand lens. Also, seminal fluid analysis was done to each male participate in this study (according to WHO 2010). Observations made were recorded with respect to age, SFA, and phalanges. Analysis of data was done using SPSS (version 16.0, SPSS Inc., Chicago, IL, USA) for frequencies and percentages. A $P$ value $<0.05$ was considered statistically significant.

\section{Results:-}

As shown in the table (1) a high significant $\mathrm{P}<0.01$ between study and control of age group. In This study the total number of patients were 350 male. In study group three hundred male their mean $(29.9 \pm 0.402 \mathrm{SE})$ and in control group fifty male included $(34.8 \pm 1.04 \mathrm{SE})$.

Table (1):- Descriptive of total number of persons include (study and control groups) for age group.

\begin{tabular}{|l|l|l|l|}
\hline Group & No. & Mean & SE \\
\hline Study & 300 & $\mathbf{2 9 . 9}$ & $\mathbf{0 . 4 0 2}$ \\
\hline Control & 50 & $\mathbf{3 4 . 8}$ & $\mathbf{1 . 0 4}$ \\
\hline
\end{tabular}

$\mathrm{P}<0.01$ High significant

There was no significant difference in body mass index between study and control groups $(\mathrm{P}>0.05)$. The mean of BMI in the study group was (29.03 $\pm 0.948 \mathrm{SE})$ and mean of BMI in control group was (29.29 $\pm 0.715 \mathrm{SE})$ as shown table (2).

Table (2):- Descriptive of BMI group by study and control

\begin{tabular}{|l|l|l|}
\hline Group & Mean & SE \\
\hline Study & 29.03 & 0.948 \\
\hline Control & 29.29 & 0.715 \\
\hline
\end{tabular}

$p=0.244 \mathrm{P}>0.05$ Non significant

Table (3):- Descriptive of Concentration $\mathrm{x}\left(10^{6}\right)$ group by study and control

\begin{tabular}{|l|l|l|}
\hline Group & Mean & SE \\
\hline Study & $\mathbf{3 6 . 0 1}$ & $\mathbf{1 . 9 0 7}$ \\
\hline Control & $\mathbf{5 4 . 2 4}$ & $\mathbf{4 . 4 5 9}$ \\
\hline
\end{tabular}




\section{$\mathrm{P}<0.01$ High significant}

There was high significant difference between study group and control group in the sperm concentration in the examination of seminal fluid parameter as shown in the table (3). The probability was ( $>0.01)$. The mean of study group is $(36.01 \pm 1.907)$ and the mean of control group is $(54.24 \pm 4.459)$.

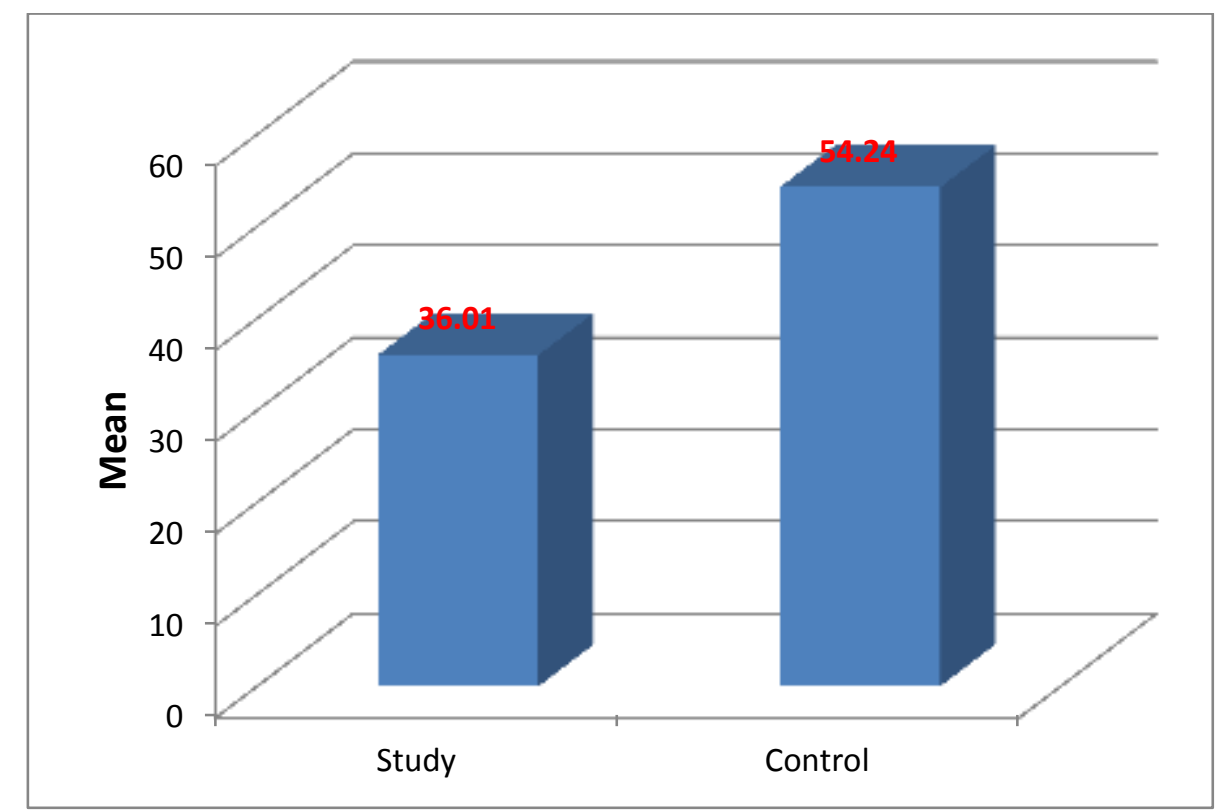

Figure (3):- Descriptive of Concentration $\mathrm{x}\left(10^{6}\right)$ group by study and control

The figure (3) clarify a significant difference between the group study and control group in the sperm concentration as shown in the figure above.

Table (4):- Descriptive of Normality (\%) group by study and control

\begin{tabular}{|l|l|l|}
\hline Group & Mean & SE \\
\hline Study & 24.01 & 0.952 \\
\hline Control & 32.42 & 1.485 \\
\hline
\end{tabular}

$\mathrm{p}=0.049 \mathrm{P}<0.05$ Significant

There was significant difference in the normality between study and control groups $(\mathrm{P}>0.05)$ as shown in table 4 . The mean of study group is $(\mathbf{2 4 . 0 1} \pm \mathbf{0 . 9 5 2})$ and mean of control group is $(\mathbf{3 2 . 4 2} \pm \mathbf{1 . 4 8 5})$. 


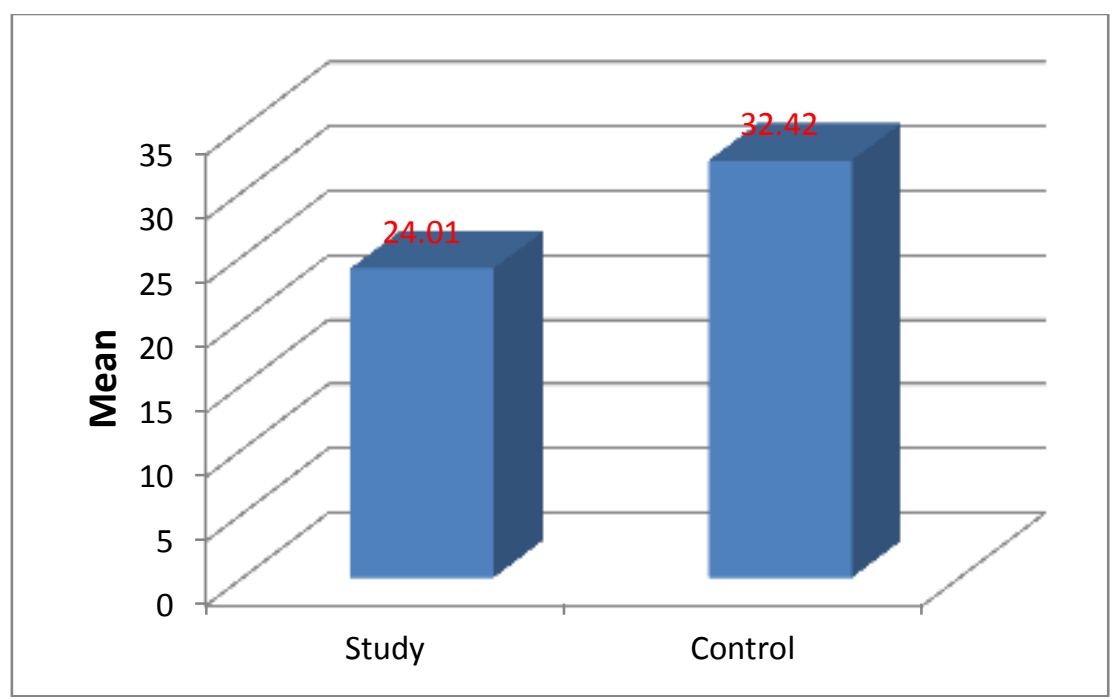

Figure (4):- Descriptive of Normality (\%) group by study and control

In the figure 4 the description of normality percentage drawn as a graph to clarify this significance difference as mentioned above in the table 4.

Table (5):- Descriptive of Motility (\%) group by study and control

\begin{tabular}{|l|l|l|l|l|l|l|}
\hline \multirow{2}{*}{} & \multicolumn{2}{|l|}{ Progressive } & \multicolumn{2}{l|}{ Non- Progressive } & \multicolumn{2}{l|}{ Immotile } \\
\cline { 2 - 7 } & Mean & SE & Mean & SE & Mean & SE \\
\hline Study & 24.21 & 0.988 & 23.59 & 0.835 & 37.86 & 1.424 \\
\hline Control & 30.78 & 1.637 & 31.8 & 1.039 & 32.42 & 1.485 \\
\hline P-value & 0.214 & P & HS & & 0.038 & NS \\
\hline Sig & NS & HS & & \\
\hline
\end{tabular}

To study the motility percentage for the sperm in seminal fluid analysis as shown in the table (5) there was a high significant difference between study and control group $(\mathrm{P}<0.01)$ of Non- Progressive. The mean of study group (23.59 \pm 0.835$)$ and mean of control group (31.8 \pm 1.039$)$.

For description of presence of hair distribution on the dorsum of phalanges of the hand of human beings especially on the index, middle, ring and little phalanges in the right and left hands. The study proofs that the proximal phalanges in all fingers have the high percentages of presence of hair in both hands (right and left) as clarified in the table (6) below.

Table (6):- Descriptive Of Fingers Sheet Of Study N=300

\begin{tabular}{|l|l|l|l|l|l|l|l|l|}
\hline \multirow{3}{*}{ Fingers } & \multicolumn{4}{l}{ Left Hand Phalanges } & \multicolumn{4}{l|}{ Right Hand Phalanges } \\
\cline { 2 - 9 } & Proximal & \multicolumn{3}{l}{ Middle } & Proximal & Middle \\
\cline { 2 - 9 } & No. & $\mathbf{\%}$ & No. & $\mathbf{\%}$ & No. & $\mathbf{\%}$ & No. & \% \\
\hline Index & 288 & 96.0 & 6 & 2.0 & 283 & $\mathbf{9 4 . 3}$ & 3 & 1.0 \\
\hline Middle & 292 & $\mathbf{9 7 . 3}$ & 60 & 20.0 & 289 & $\mathbf{9 6 . 3}$ & 58 & 19.3 \\
\hline Ring & 290 & $\mathbf{9 6 . 7}$ & 103 & $\mathbf{3 4 . 3}$ & 288 & 96.0 & 100 & 33.3 \\
\hline Little & 286 & $\mathbf{9 5 . 3}$ & 25 & $\mathbf{8 . 3 3}$ & 282 & 94.0 & 26 & 8.67 \\
\hline
\end{tabular}

Table (7):- Compare between Study and control

\begin{tabular}{|l|l|l|l|l|}
\hline \multirow{3}{*}{ Phalanges } & \multicolumn{2}{|l|}{ Left Hand Phalanges } & \multicolumn{2}{l|}{ Right Hand Phalanges } \\
\cline { 2 - 5 } & Proximal & Middle & Proximal & Middle \\
\cline { 2 - 5 } & $P$ value & $P$ value & $P$ value & $P$ value \\
\hline Index & $0.048^{*}$ & $0.082^{* *}$ & $0.047^{*}$ & $1.00^{* *}$ \\
\hline Middle & $0.046^{*}$ & $0.047^{*}$ & $0.045^{*}$ & $0.102^{* *}$ \\
\hline Ring & $0.043^{*}$ & $0.007^{*}$ & $0.042^{*}$ & $0.046^{*}$ \\
\hline
\end{tabular}




\begin{tabular}{|l|l|l|l|l|}
\hline Little & $0.047^{*}$ & $0.042^{*}$ & $0.044^{*}$ & $0.047^{*}$ \\
\hline$* \mathbf{P}<\mathbf{0 . 0 5}$ Significant & $* * \mathbf{P}>\mathbf{0 . 0 5}$ Non significant &
\end{tabular}

The table (7) clarify in total result was shown a significant difference between study group and control group in hair distribution on phalanges on dorsum of the fingers of right and left hands. In left hand phalanges of proximal and middle $(\mathrm{P}<0.05)$ but on index there was non-significant $(\mathrm{P}>0.082)$. While significant difference $(\mathrm{P}<0.05)$ in proximal of right hand phalanges. Non-significant $(\mathrm{P}>0.05)$ in index and middle fingers of right hands $(1.00$. \& 0.102 respectively)

\section{Discussion:-}

The variation of distribution of hair on the dorsum of phalanges of human male depend on hormonal effects and may be a good monitor for seminal fluid parameters. The absence of hair on the proximal phalanges of $2 \%$ of some subjects is in line with what has been reported in other populations-South of Spain (Luna, 1989) ${ }^{(13)}$, in Italy (Vona and porcella, 1989) ${ }^{(12)}$, Southh India (Sethuraman et al, 1982) ${ }^{(14)}$. Calabar, Nigeria (Singh, 1982) ${ }^{(5)}$, Indians (Dutta, 1965) ${ }^{(15)}$. HOXC13 is the only member of the HOX multigene family that produces a fragile hair phenotype. HOXC13 is expressed in the human anagen hair follicle, a direct involvement of HOXC13 in the control of hair keratin expression during early trichocyte differentiation ${ }^{(16)}$.

The distribution of phalangeal hairs has been studied in different societies such as Turkey (Hatiboglu, 1983) ${ }^{(7)}$, kanuri and Baburs of Northwest Nigeria (Mbjiorgu, 1996) ${ }^{(17)}$. The phalangeal hair distribution in different parts of world have revealed the difference in the pattern of arrangement of hair in proximal and middle phalanges in many studies ${ }^{(18)}$.

The higher frequency of distribution of hair in males attributed to dorsum of proximal phalanx of fingers in the left hands except on middle phalanges of index finger while on the right hands are of significant variations on all phalanges except on middle phalanges of index and middle fingers. These observations are clear if looks to table 7 .

There was a high significant difference between study and control group $(\mathrm{P}<0.01)$ of Non- Progressive. The mean of

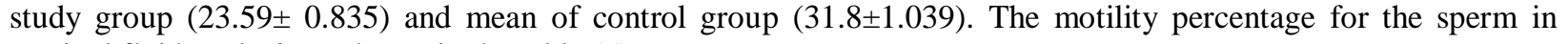
seminal fluid analysis as shown in the table (5).

\section{References:-}

1. Jungueira, C. and Carneiro, J. (2005). The Hair Basic Histology. Text and atlas. 11th edition. MC Graw Hill Co. Inc. USA, 368-369.

2. Harrison, J. L. and Davies, K. D. (1999). Cold evoked pain varies with skin types and cooling rates. A psychophysical study in humans. Pains83 (2) $123-135$.

3. Williams, P., Bannister, L. H., Borry, M. M. Collins, P., Dyson, M., Dussak, J. E. and Ferguson, M. W. (2005). Hair: In Gray's Anatomy. (38th Ed.) Elsevier, Philadelphia, 1226.

4. Dharap AS, Lim BC and Ong LB: Distribution of hair on the dorsum of the phalanges of the hand in a Chinese population from Malaysia. Anthropol Anz. (1996) Des; 54(4): 311-6.

5. Singh, J. D. (1982). Distribution of hair on the phalanges of the hand in Nigerians. Acta anatomica 112, 31-35.

6. Tiwari SC \& Bhasin MK: A note on the distribution of middle phalangeal hair among Tibetans. American Journal of Physical Anthropology (1969) 31, 429-431

7. Hatiboglu MT: The hair distribution of the phalanges of the hand among Turks. J. Anat. (1983), 137, 3, pp. 537540.

8. Dharap AS, Varma SL \& Chary TV: Hair distribution on the phalanges of the hands in Malays Anthropol Anz. 1994 Dec; 52(4):315-20.

9. Olabiyi AO, Akpantah AO, Oyerinde OF, Gbotolorun SC, Eluwa MA, Ekanem TB: The distribution of hair on the phalanges of a sample population of Nigerian Yorubas in relation to sex, age and job type. Niger J Physiol Sci. 2008 Jun-Dec; 23(1-2):101-4.

10. Sinha DN, Asthana AK, Sharma D.: Incidence, pattern and direction of hair distribution on the dorsum of phalanges of the hands of male medical students of Uttar Pradesh, India. Anthropol Anz. 1984 Mar; 42(1):4752.

11. Esteban E. and Fananas L.: Middle phalangeal hair in two Mediterranean Spanish populations. International Journal of Anthropology. (1992) Vol. 7 No.4 (61-66). 
12. Vona G, Porcella P.:Middle phalangeal hair distribution in a Sardinian population sample. Anthropol Anz. 1989 Mar; 47(1):79-85.

13. Luna, F. (1989). Distribution of middle phalangeal hair in a population of South Spain. Anthropol. Anz 47 (1): $73-78$.

14. Sethuraman, M., Srikanth, N. S., Ramaaana Roa, K.V. and Swami, K. S. (1982). Distribution of middle phalangeal in two groups of Srivaishnava Brahmins of Tirupati (South India), Anthropol. Anz 40 (4).

15. Dutta, P. C. (1965). Variability of middle phalangeal hair among Indian population. J. Royal Anthropol. Institute of Great Britain and Ireland, 95:115 - 126.

16. Jave-Suarez LF et.al :HOXC13 Is Involved in the Regulation of Human Hair Keratin Gene Expression. The Journal of biological chemistry. (2002) Vol. 277, No. 5, pp. 3718-3726,

17. Mbajiorgu, F,E., Asala S.A., Ejinwunmi A. B., Abdullahi, Z. (1996). Hair distribution on the phalanges of the hand among Kanuri and Baburs / Buras of Northwest Nigeria. Acta Anatomica 157 (4) 324 - 329.

18. Sadakat Ali, Nidhi Sharma, Raghuveer Singh Mandloi and Dilshad Usmani: A STUDY OF DISTRIBUTION OF HAIR ON THE PHALANGES OF HAND IN NORTH INDIA. Innovative Journal of Medical and Health Science 3: 1 Jan - Feb (2013) 26 - 28. 